\title{
Relationship of lung function to radiographic reading (ILO) in patients with asbestos related lung disease
}

\author{
J E COTES, B KING
}

From the University Department of Occupational Health and Hygiene, Medical School, Newcastle upon Tyne

\begin{abstract}
The 1980 International Labour Office (ILO) classification of posteroanterior chest radiographs was used to obtain the scores for profusion of small opacities and pleural abnormalities of 172 men with confirmed or suspected disease of the lungs due to asbestos. After allowance had been made for age, stature, and smoking habit the quantitative score for area of diffuse pleural thickening seen in profile on both lateral chest walls contributed to reductions in inspiratory capacity, expiratory reserve volume, and forced expiratory flow rates. Occlusion of one or both costophrenic angles in the presence of diffuse thickening was associated with further reduction in inspiratory capacity. Profusion of small opacities was associated with a reduction in transfer factor. Diffuse pleural thickening and occlusion of costophrenic angles were associated with relatively low values for the forced expiratory flow rates $\left(\mathrm{MEF}_{50} \mathrm{FVC}\right)$ and $\mathrm{FEV}_{1} / \mathrm{FVC}$, whereas small opacities were associated with relatively high values. Thus overall increased, normal, or reduced values of $M E F_{50} F V C$ and $\mathrm{FEV}_{1} / \mathrm{FVC}$ might occur, depending on the distribution of the radiographic abnormalities. The findings contribute to the validation of the ILO pleural scores; those for diffuse pleural thickening and occlusion of costophrenic angles should be used jointly with the scores for profusion of parenchymal small opacities in interpreting the lung function of persons exposed to asbestos.
\end{abstract}

\section{Introduction}

The International Labour Office (ILO) international classification of radiographs of pneumoconioses' is used to describe the posteroanterior chest radiograph. It was developed initially for the round opacities of coalworkers' pneumoconiosis and subsequently extended to the irregular opacities of asbestosis and to abnormalities of the pleura. The latter comprised chest wall plaques with or without calcification, diffuse pleural thickening, diaphragmatic thickening and plaques, and obliteration of one or both costophrenic angles. In many studies the types and profusion of small opacities have been shown to relate to occupational exposure and to clinical outcome. Less clinical information is available for the pleural abnormalities, partly because most of those affected are symptom free and the remainder frequently also have asbestosis. Evidence that pleural changes are

Address for reprint requests: Dr J E Cotes, Respiration and Exercise Laboratory, Department of Occupational Health, Medical School, Newcastle upon Tyne NE2 4HH.

Accepted 19 July 1988 associated with respiratory impairment was reported for Quebec asbestos workers ${ }^{2}$ and subsequently for smaller groups studied in detail. ${ }^{3-5}$ Confirmation was provided by Britton. ${ }^{6}$ Others made a clear distinction between the effects of plaques and of diffuse pleural thickening, ${ }^{7-10}$ and this led to recognition of the latter condition for pneumoconiosis disability benefit in the UK."

The effects of pleural abnormalities may interact with those of diffuse small opacities, so the present study made use of multivariate analysis to assess the influences of both on lung function.

\section{Methods}

\section{SUBJECTS}

The subjects were 172 men referred from the Newcastle Pneumoconiosis Medical Panel for assessment of lung function on account of confirmed or suspected disease of the lungs due to asbestos; they comprised mainly laggers and tradesmen who worked alongside them, but also men engaged in the manufacture of products containing asbestos. Referral was from the medical boarding centre (respiratory diseases) that the men had attended, usually because an abnormality had been detected at the routine periodic examination. 


\section{READING THE RADIOGRAPHS}

All the men had posteroanterior and two oblique chest radiographs. The former were read for pleural abnormalities and small parenchymal opacities according to the ILO classification' by three experienced observers (PCE, AEC, and $\mathrm{KMcC}$ ) working independently. If they were in doubt, two of the readers looked at the oblique films before coming to a decision. The readers had previously agreed on trigger films, which were then interspersed with the others, and the agreed reading was disclosed after each had been read. Diffuse pleural thickening was recorded only when seen in profile along the chest wall. The median readings for each film were extracted subsequently.

\section{INVESTIGATIONS}

When the subject attended the laboratory an occupational history was obtained and the 1976 Medical Research Council questionnaire on respiratory symptoms (obtainable from 20 Park Crescent, London W1N 4AL) was completed. A clinical examination of the respiratory system was carried out with special reference to the presence or absence of end inspiratory crepitations and finger clubbing. The assessment of lung function included measurements of ventilatory capacity by dynamic spirometry, transfer factor for the lung by the single breath carbon monoxide method (TLCO), and measurement of the physiological response to progressive exercise on a treadmill. Spirometry was performed with a dry bellows spirometer (McDermott) with digital display of forced expiratory volume $\left(\mathrm{FEV}_{1}\right)$, forced vital capacity (FVC), peak expiratory flow rate (PEF), and flow rates when $50 \%$ and $25 \%$ of the vital capacity remained to be expired $\left(\mathrm{MEF}_{50} \mathrm{FVC}\right.$ and $\mathrm{MEF}_{25} \mathrm{FVC}$ respectively). Before use a volume calibration was carried out with a gas syringe and the timing was checked by using a weight and standard orifice. Three technically satisfactory results were obtained and the highest value for each index was included in the analysis.

Stature was measured during vertical traction to the head with a stadiometer (Harpenden). Fat free mass was obtained from body mass, measured with a calibrated spring balance, and percentage body fat estimated by the method of Durnin and Womersley. ${ }^{1213}$

Total lung capacity and its subdivisions (residual volume, expiratory reserve volume, and inspiratory capacity) were measured by closed circuit spirometry with helium as the indicator gas. For TLCO measurements a gas mixture containing $0.3 \%$ carbon monoxide and $14 \%$ helium in air was used. A transfer test apparatus (PK Morgan) was used and the gas analysers were calibrated by standard methods. ${ }^{14}$ The breath holding time included two thirds of the in- $\stackrel{\vec{F}}{?}$ spiratory time, the time of deadspace washout, ando half the time of sample collection. ${ }^{15}$ Alveolar volume $\frac{\bar{\sigma}}{\bar{N}}$ was the volume inspired plus the residual volume $\frac{\bar{s}}{\frac{}{\sigma}}$ measured by closed circuit spirometry. Transfer $\stackrel{\mathbb{}}{\varrho}$ coefficient (KCO) was derived from TLCO and alveolar volume. Standard reference values were $\vec{\circ}$ used. ${ }^{13}$

Treadmill exercise was performed with an initial $\overrightarrow{\vec{\omega}}$ belt speed of $1 \mathrm{~km} / \mathrm{h}$; this was increased by $0.5 \mathrm{~km} / \mathrm{h} \stackrel{\text { }}{\rightleftharpoons}$ each minute up to $4.0 \mathrm{~km} / \mathrm{h}$. The belt was then $\overrightarrow{\times}$ inclined to $4^{\circ}$ and thereafter the loading was $\stackrel{\vec{\omega}}{+}$ increased by a further $1^{\circ}$ or $0.5 \mathrm{~km} / \mathrm{h}$ each minute $-\overrightarrow{-}$ until a suitable endpoint. This was when the subject ${ }^{\circ}$ chose to stop, the cardiac frequency rose to $80 \%$ of $\forall$ the predicted maximum, ${ }^{16}$ or the electrocardiogramo (recorded from chest leads in the CM5 configuration $^{17}$ ) showed evidence of ischaemia. Ventila- $O$ tion was measured with a vane anemometer $\left(\mathrm{PK}_{\stackrel{O}{O}}^{\bigcirc}\right.$ Morgan), and the oxygen and carbon dioxide content of mixed expired gas were used to obtain the minute by minute relationship of ventilation to con- $\bar{\oplus}$ sumption of oxygen, and hence by interpolation the ${ }^{\circ}$ ventilation at an oxygen consumption of $45 \mathrm{mmol} / \mathrm{O}$ min $\left(\dot{\mathrm{V}}_{45}\right)$. The corresponding index of cardiac frequency $\left(\mathrm{fC}_{45}\right)$ was obtained concurrently. The plot of ventilation against tidal volume was used to obtain the tidal volume at a minute volume of $30 \mathrm{l} / \stackrel{\mathbb{Q}}{\varrho}$ $\min \left(\mathrm{VT}_{30}\right)$. The maximal oxygen uptake $\left(\dot{\mathrm{n}}_{2} \mathrm{max}\right) \underset{\overrightarrow{\mathrm{O}}}{\vec{\prime}}$ achieved during the progressive exercise test was also 3 recorded. Details of the procedures are given elsewhere. $^{13}$

\section{ANALYSIS}

Stature and lung function measurements were treated as continuous variables, and current smoking and a $\frac{\sigma}{3}$ history of pleurisy or pneumonia as categorical variables (yes/no). The appropriateness of the different ways of categorising ex-smokers was assessed in terms of the proportion of total variance in the lung function? indices that was explained by the multiple regression $\frac{7}{8}$ analyses. For most indices the highest proportion was explained by including those who had given upN smoking up to 10 years ago with the smokers and those who had given it up more than 10 years ago with the non-smokers. With this convention 152 of the $172 \mathrm{~W}$ subjects were smokers. The radiographic readings? were scored 1-12 in both lungs for profusion of smalle opacities and $0-3$ in each lung for width and extent of chest wall pleural thickening and extent of pleural ${ }^{\circ}$ calcification. Categorical variables were used for the presence or absence in each lung of diffuse pleural thickening along the chest wall, plaques, thickening? face on, diaphragmatic thickening, occlusion of å costophrenic angle, and calcification along the dia-O phragm and chest wall and at other sites. Pleuralo 
abnormalities were entered separately for the right and left lungs.

The first stage in the analysis was to simplify and condense the radiographic information by inspection, use of two by two tables, simple correlation analysis, and principal component analysis. ${ }^{18}$ From these processes four terms emerged, of which three were unambiguous. Diffuse pleural thickening seen in profile on the chest wall was best described by the product of its thickness and its extent (each scored 0-3 for each hemithorax), designated chest wall pleural thickening; occlusion of costophrenic angles was present or absent on each side of the chest. Disease of lung parenchyma was described by the profusion of small opacities and scored 1-12.

The presence of pleural plaques was correlated with pleural thickening face on, diaphragmatic thickening and all indices of pleural and diaphragmatic calcification except "other" pleural calcification (that is, pericardial etc). The information contained in these scores could be condensed into one term, comprising pleural plaques (PPI, yes/no) plus diaphragmatic thickening (DT, yes/no), no reference being made to calcification. This term, designated PPIDT, was used in the final analysis. Two alternative indices, reflecting separately pleural plaques plus calcification and diaphragmatic thickening plus calcification, were also constructed. They were highly correlated so only one was used at a time in the analysis. Each gave results similar to those obtained with the overall index.

The radiological scores for the three readers were compared and found to be concordant in the case of pleural plaques, diaphragmatic thickening, and occlusion of costophrenic angles. One reader out of the three produced systematically lower scores for chest wall thickening and another for profusion of small opacities. Separate analysis of the results using the scores for individual readers, however, led to the same conclusions as for the median readings; the latter were therefore used as independent variables in the multiple regression analysis. The other independent variables were the "nuisance" variables age, stature, body mass index (body mass divided by stature ${ }^{2}$ ), smoking, and a history of pleurisy or pneumonia. The physiological indices were the dependent variables. The independent variables were entered one at a time starting with whichever most reduced the unexplained variance. Initially the indices were entered as linear variables; they were also entered after logarithmic transformation, which had the effect of improving the symmetry of distribution of some indices. In the event the two methods gave similar results and only those based on linear scores are reported. An IBM 370 computer was used with the SPSSX package of statistical programs for the social sciences of the University of Michigan. ${ }^{19}$ The $5 \%$ level of probability was accepted as significant.

\section{Results}

Lung function measurements and other information about the subjects is summarised in table 1 and the distribution of radiological abnormalities, based on median readings, in table 2 .

\section{RADIOGRAPHIC SCORES}

With the exception of profusion of small opacities all the radiological scores were scored for each lung separately. The scores for the right lung alone explained more of the variance in lung function than those for the left lung alone but the difference was small; the scores were summed for the final analysis.

Table 1 Mean results for the subjects $(n=172)$

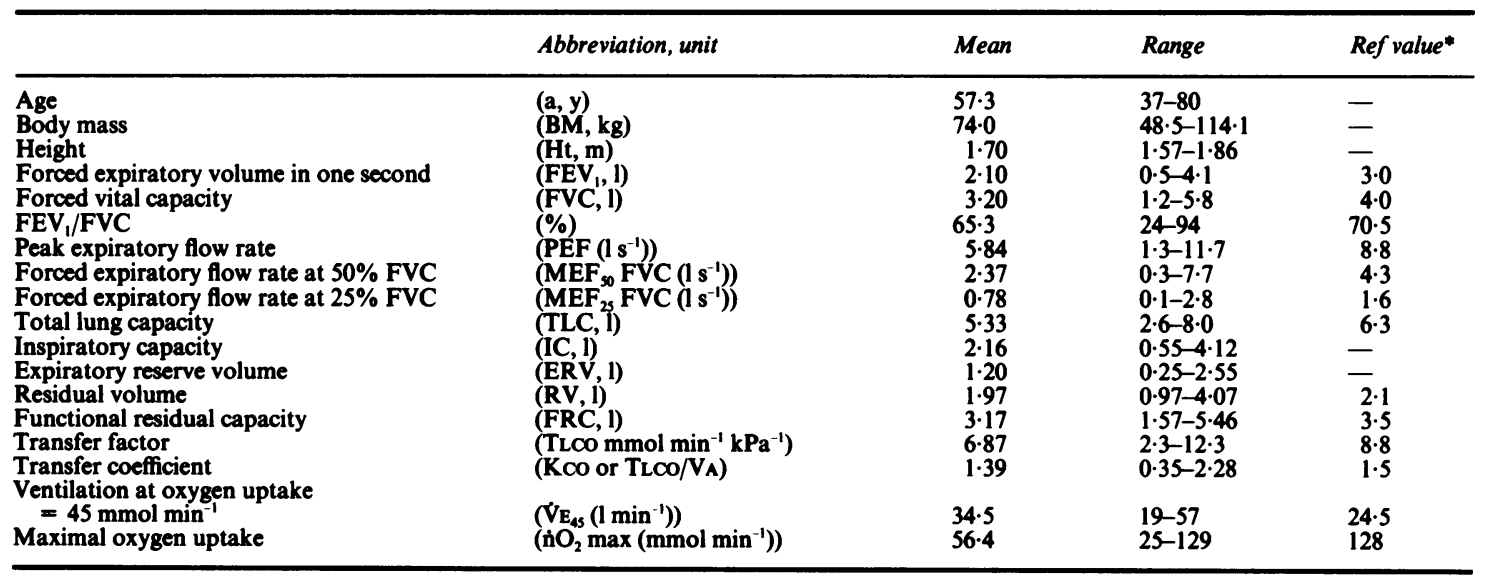

*For age $57 \mathrm{y}$, height $1.7 \mathrm{~m} .^{13}$ 
Table 2 Distribution of radiological abnormalities

\begin{tabular}{|c|c|c|c|c|}
\hline \multirow[b]{2}{*}{ Abnormality } & \multirow[b]{2}{*}{ Absent } & \multicolumn{2}{|c|}{ No of unilateral cases } & \multirow{2}{*}{$\begin{array}{l}\text { No of } \\
\text { bilateral cases }\end{array}$} \\
\hline & & Right & Left & \\
\hline $\begin{array}{l}\text { Diffuse pleural thickening } \\
\text { Pleural plaques } \\
\text { Pleural thickening on diaphragm } \\
\text { Occlusion of costophrenic angle } \\
\text { Pleural calcification on wall } \\
\text { Pleural calcification on diaphragm }\end{array}$ & $\begin{array}{r}62 \\
124 \\
96 \\
135 \\
128 \\
115\end{array}$ & $\begin{array}{r}36 \\
11 \\
21 \\
15 \\
6 \\
11\end{array}$ & $\begin{array}{r}14 \\
9 \\
11 \\
12 \\
6 \\
13\end{array}$ & $\begin{array}{l}60 \\
28 \\
44 \\
10 \\
32 \\
33\end{array}$ \\
\hline Profusion of small opacities by category (Cat) & Cat0:31 & Cat1:85 & Cat2:44 & Cat3:12 \\
\hline
\end{tabular}

Table 3 Details of radiological indices

\begin{tabular}{lll}
\hline & Reading score & Mean (range) \\
\hline $\begin{array}{l}\text { Chest wall thickening } \\
\text { width } \times \text { extent (CWT) }\end{array}$ & $(0-3) \times(0-3)^{*}$ & $4.49(0-18)$ \\
$\begin{array}{c}\text { Occlusion of costophrenic } \\
\text { angle (OCPA) }\end{array}$ & Yes/not* & $0.27(0-2)$ \\
$\begin{array}{l}\text { Pleural plaques plus } \\
\text { diaphragmatic thickening } \\
\text { (PPIDT) }\end{array}$ & Yes/no + yes/not* 1.14 (0-4) \\
$\begin{array}{l}\text { Profusion of small opacities } \\
\text { (prof) }\end{array}$ & $1-12$ & $5.63(2-11)$ \\
\hline
\end{tabular}

For each hemithorax separately.

†Yes $=1$, no $=0$.

The resulting mean values and ranges for the variables chest wall thickening, PPIDT, occlusion of costophrenic angles, and profusion of small opacities are given in table 3 . The scores for chest wall thickening and occlusion of costophrenic angles were correlated $(r=0.49)$ because 36 of the 37 men with occlusion of costophrenic angles also had diffuse pleural thickening. The score for chest wall thickening was greater in the men with occlusion of one or both costophrenic angles than in the remainder (mean scores respectively 8.92 and $3.27 ; p<0.01$ ). With this exception the derived radiological indices were independent of each other.

\section{SMOKING HISTORY}

The smokers (including ex-smokers up to 10 years) had evidence of airway obstruction on all measures of forced expiratory flow, and defective gas transfer and Kco by comparison with the non-smokers (including long term ex-smokers). Lung function did not differ between heavy and moderate or light smokers. The extent of pleural disease was unrelated to smoking but the score for profusion of small opacities was greater in the smokers.

\section{RELATIONSHIP OF RADIOGRAPHIC SCORES TO LUNG FUNCTION (table 4) Chest wall thickening}

After the nuisance variables had been allowed for, the score for chest wall thickening was associated with a reduction in inspiratory capacity, expiratory reserve volume, total lung capacity, forced expiratory volume, and other indices of forced expiratory flow. The proportion of variance explained by chest wall thickening was greatest in the case of FVC, where it was about one quarter of the total. Chest wall thickening was unrelated to $\mathrm{FEV}_{\mathrm{l}} / \mathrm{FVC}$, residual volume, TLCO, $\mathrm{KCO}$, or the physiological response to exercise.

\section{Occlusion of costophrenic angles}

Filling of one or both costophrenic angles was

Table 4 Partial regression coefficients of lung function indices on the radiological variables (parentheses contain the percentage of varianee associated with individual radiological scores*)

\begin{tabular}{|c|c|c|c|c|c|c|c|c|c|c|}
\hline & Age & Height & $B M / H t^{2}$ & $S m$ & Pneum & $C W T$ & $O C P A$ & PPIDT & Prof & $R^{2}(0$ \\
\hline 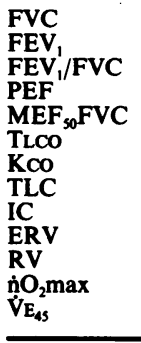 & $\begin{array}{l}-0.03 \\
-0.03 \\
-0.24 \\
-0.08 \\
-0.05 \\
-0.05 \\
-0.01 \\
-0.02 \\
0.02 \\
-1.0\end{array}$ & $\begin{array}{l}4.05 \\
2.54 \\
5.57 \\
\\
6.04 \\
\\
5.85 \\
1.81 \\
2.16 \\
1.77 \\
68.4 \\
31.8\end{array}$ & $\begin{array}{r}0.09 \\
0.12 \\
0.03 \\
0.04 \\
-0.03 \\
-0.03 \\
1.8\end{array}$ & $\begin{array}{l}-0.48 \\
-14.20 \\
-1.20 \\
-1.55 \\
-1.69 \\
-0.33 \\
-0.35 \\
0.50\end{array}$ & 0.22 & $\begin{array}{l}-0.06(8.4) \\
-0.4(7.7) \\
-0.10(3.9) \\
-0.09(3.4) \\
\\
-0.07(7.6) \\
-0.03(2.3) \\
-0.02(3.0)\end{array}$ & $\begin{array}{l}-0.27(2.5) \\
-0.27(3.4) \\
-3.84(2.7) \\
-0.59(1.4) \\
-0.60(2.1) \\
-0.28(15.0)\end{array}$ & $\begin{array}{l}0.15(5.0) \\
0.12(3.3) \\
0.28(1.8) \\
0.29(3.1) \\
0.06(2.3)\end{array}$ & $\begin{array}{c}1.23(3.9) \\
0.12(2.7) \\
-0.34(20.1) \\
-0.04(5.6) \\
-0.11(5.5) \\
-0.04(1.5) \\
-0.05(2.9) \\
-1.40(2.0) \\
1.07(4.1)\end{array}$ & $\begin{array}{l}41 \cdot 2 \\
46 \cdot 4 \\
15 \cdot 6 \\
30 \cdot 0 \\
29 \cdot 9 \\
44 \cdot 1 \\
27 \cdot 9 \\
23 \cdot 4 \\
37 \cdot 8 \\
30 \cdot 2 \\
14 \cdot 8 \\
34 \cdot 8 \\
10 \cdot 8\end{array}$ \\
\hline $\begin{array}{l}\text { *For abbrevi } \\
\text { †Total varian } \\
\text { Sm-smokin }\end{array}$ & $\begin{array}{l}\text { is an } \\
\text { xplai } \\
\text { seum }\end{array}$ & $\begin{array}{l}\text { see tal } \\
\text { ludin } \\
\text { monia }\end{array}$ & $\begin{array}{l}\text { and } 3 . \\
\text { ariables. }\end{array}$ & & & & & & & \\
\hline
\end{tabular}


associated with a reduction of inspiratory capacity, accounting for $40 \%$ of the explained variance. Occlusion of costophrenic angles was also associated with reductions in $\mathrm{FVC}, \mathrm{FEV}_{1}, \mathrm{FEV}_{1} / \mathrm{FVC}$, peak expiratory flow (PEF), and TLCo. It was unrelated to the flow rates at small lung volumes, $\mathrm{KCO}$, or the physiological response to exercise.

\section{Pleural plaques and diaphragm thickness}

Scores for pleural plaques and diaphragm thickening separately or in combination and with or without calcification were correlated positively with forced vital capacity and related indices of forced expiratory flow. PPIDT was unrelated to total lung capacity, inspiratory capacity, $\mathrm{MEF}_{25} \mathrm{FVC}$, TLCO, KCO, and the physiological response to exercise.

\section{Small opacities}

Profusion of small opacities affected primarily TLCo, where it accounted for nearly half of the explained variance $(20 \%$ out of a total of $44 \%)$. Kco was also reduced and there were reductions in residual volume, inspiratory capacity, and total lung capacity but not in FVC or $\mathrm{FEV}_{1}$. Profusion was associated positively with the ventilatory response to exercise $\left(\dot{\mathrm{VE}}_{45}\right)$ and negatively with the maximal oxygen uptake. There were positive associations with $\mathrm{FEV}_{\mathrm{l}} / \mathrm{FVC}$ and $\mathrm{MEF}_{50} \mathrm{FVC}$ but no associations with PEF or $\mathrm{MEF}_{25} \mathrm{FVC}$ or with expiratory reserve volume.

\section{Discussion}

The study provided detailed information on the relation of the ILO classification of pleural abnormalities to lung function in patients with asbestos related lung disease. The abnormalities were frequently multiple and some were scored under more than one heading, so there was need for rationalisation before their contributions to lung function could be assessed. The contributions of the right and left lungs were slightly different but no material error was introduced by using a simple additive model weighting the scores in the ratio 1:1. The smoking indices needed to take into account that in the 10 years before the study many of the subjects had stopped smoking, and also that pack years correlated with age and so this variable was unsuitable for inclusion with age in the multiple regression analysis. The alternative of using categorical (yes/no) variables with those who had stopped smoking up to 10 years ago treated as smokers was shown to be valid.

The score for profusion of small opacities was independent of the other scores and suitable for inclusion in the analysis without modification. Subject to the important reservation considered below, this was also true for occlusion of costophrenic angles.
Diffuse pleural thickening along the lateral chest wall was described by scores for presence or absence, width, and extent. All these scores were related to lung function. The strongest association was with the product of width and extent and hence area of thickening; this was independent of the scores for other pleural and diaphragmatic abnormalities. The latter were intercorrelated and adequately represented by the score for pleural plaques and diaphragmatic thickening (PPIDT). This index was highly correlated with the score for calcification, though calcification itself was not related to the lung function. Thus the four radiographic indices used in the analysis both described the available information and were effectively independent, so they could be used together in the multiple regression analysis. The other independent variables (see under "Analysis") were not significantly intercorrelated; their contributions to the description of lung function were in line with expectations, except for a history of pneumonia, which was associated with an increased $\mathrm{FEV}_{1}$. Omitting this variable did not alter the other results.

The radiographic indices contributed more than half the explained variance in TLC, IC, and TLCo but they did not contribute to the variance seen in exercise cardiac frequency, or in exercise tidal volume even after standardisation for vital capacity. Chest wall thickening was associated with a restrictive ventilatory defect and reduction in forced expiratory flow rates at both large and small lung volumes. There was no association with defective gas transfer or limitation to exercise, although this had been expected in view of earlier work. ${ }^{920}$ The point is taken up below.

Filling of one or both costophrenic angles was associated with limitation to lung expansion from FRC (IC reduced); the limitation affected the FVC and related variables, but not the $\mathrm{KCO}$. The effects on the FVC and indices of forced expiratory flow were of similar magnitude to and additional to those due to diffuse pleural thickening. The men with occlusion of costophrenic angles, however, were in general those with extensive chest wall thickening. In the computer program the effect of chest wall thickening in these men was allowed for by extrapolation from the results for the 74 men with chest wall thickening but no occlusion of costophrenic angles. Linear and proportional models gave similar results but owing to the overlap of abnormalities the effect of occlusion of costophrenic angles alone could not be assessed. The present results show that occlusion of costophrenic angles had important implications for lung function in men who also had diffuse pleural thickening due to asbestos. The study did not provide information on the effects of different aetiologies-for example, previous pleural effusions unrelated to asbestos or other inflammatory processes-or of the extent of the 
occlusive lesion other than whether it occurred on one or both sides of the chest.

The presence of small opacities was closely related to the reduction in transfer factor, profusion accounting for about half the explained variance. In some other respects, however, the pattern of lung function was subtly different from what might have been expected. Thus profusion was associated with a reduction in residual volume but no corresponding reduction in vital capacity (the latter was associated with pleural abnormalities). Of the components of vital capacity, occlusion of costophrenic angles limited particularly the inspiratory capacity and chest wall thickening the expiratory reserve volume. Again as expected, profusion was associated with an increase in $F E V_{1} /$ FVC and the forced expiratory flow rate $\mathrm{MEF}_{\text {so }} \mathrm{FVC}$. Pleural abnormalities, however, probably by reducing lung volume, were associated with reductions in both these indices of airways calibre. Thus for $\mathrm{FEV}_{1} / \mathrm{FVC}$ and $\mathrm{MEF}_{50} \mathrm{FVC}$, after allowance for age and smoking, a normal, high, or low overall value might occur, depending on the distribution of the radiographic abnormalities.

The positive association of pleural plaques and diaphragm thickening with above average forced expiratory volumes and flow rates (table 4) was unexpected. It was probably due to preferential recruitment to the study of men with these radiographic abnormalities, but improved efficiency of diaphragmatic contraction could not be excluded on the present evidence. The absence of a significant reduction in exercise capacity in association with pleural abnormalities was also unexpected. The reason for this is not clear.

In conclusion, the present results confirmed the widely accepted association between diffuse pleural thickening and loss of lung function. The association was well described by the product of width and extent of chest wall thickening as defined in the ILO classification; in the presence of thickening, occlusion of either or both costophrenic angles exerted an additional deleterious effect. The changes in lung function were different from but additive with those due to profusion of small opacities. The results provided some validation for the use of the relevant ILO pleural indices in their present form; they also suggested that in future it should not be sufficient to relate the loss of lung function of patients with asbestosis to the profusion of small opacities alone as is sometimes still done today. ${ }^{21}$ In particular, the posteroanterior radiographic scores for area of chest wall thickening and occlusion of costophrenic angles should be taken into account.

Additional information, particularly on abnormalities of the anterior chest wall and diaphragm, would be obtained from oblique views of the thorax and from computed tomography. ${ }^{22} 23$ In the presento study oblique films were available and in some in stances consulted before deciding on a score for theo posteroanterior film by two readers but not by the third. Analysis showed that the scores were not influenced systematically on this account. From then present results more information on plaques and diaphragmatic thickening would not be helpful, but more accurate delineation of diffuse chest wall pleura $\vec{\omega}$ thickening could be of practical use.

Drs J E M Hutchinson and H S Fulton referred thei patients for assessment. Drs P C Elmes, A E Cock ${ }^{\omega}$ croft, and $\mathrm{K}$ McConnochie read the chest radiographs with administrative help from Mrs C Bevan; they also commented on the manuscript. Dr D J Chinn was responsible for the lung function assessments. Drs $\mathrm{J} \mathrm{W}_{-}^{-}$ Reed and F M El-Gamal supervised some exercise tests. Dr V Woolley provided statistical advice and Mrs M E Hyam secretarial and administrative sup-음 port. We are indebted to the Medical Research Council and the European Coal and Steel Communityo

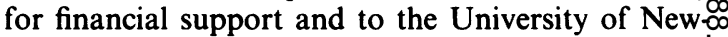
castle upon Tyne for facilities.

\section{References}

1 International Labour Office. Guidelines for the use of IL international classification of radiographs of pneumocon? ioses. Revised 1980 revision. Geneva: ILO, 1980 ? (Occupational Safety and Health Series No 22.)

2 Becklake MR, Fournier-Massey G, McDonald JC: Siemiatychi J, Rossiter CE. Lung function in relation tof chest radiographic changes in Quebec asbestos workers: 1. Methods, results and conclusions. Bull Physiopathook Respir 1970;60:637-59.

3 Harries PG, MacKenzie FAF, Sheers G, Kemp JH Oliver TP, Wright DS. Radiological survey of merB exposed to asbestos in naval dockyards. $\mathrm{Br} \mathrm{J}$ Ind Me 1972;29:274-9.

4 Arzt GH, Pirtkien R, Rosenthal H. Review of lung function data in 195 patients with asbestosis of the lung Int Arch Occup Environ Health 1980;45:63-79.

5 Rom W, Thornton J, Miller A, Lilis R, Selikoff IJN Abnormal spirometry in shipyard workers with pleuraf disease [abstract]. Am Rev Respir Dis 1977;115:239.

6 Britton MG. Asbestos pleural disease. $\mathrm{Br} J$ Dis Chest 1982;76:1-10.

7 Leathart GL. Pulmonary function tests in asbesto workers. Trans Soc Occup Med 1968;18:49-55.

8 Zitting A, Huuskonen MS, Alanko D, Mattsson T Radiographic and physiologic findings in patients with asbestosis. Scand J Work Environ Health 1978;4:275 83.

9 Wright PH, Hanson A, Kreel L, Capel LH. Respirator function changes after asbestos pleurisy. Thora 1980;35:31-6.

10 McLoud TC, Woods BO, Carrington CB, Epler GR 
Gaensler EA. Diffuse pleural thickening in an asbestosexposed population: Prevalence and causes. $A J R$ 1985;144:9-18.

11 Department of Health and Social Security. Asbestosrelated diseases without asbestosis. Social Security Act 1975. London: HMSO, 1984.

12 Durnin JVGA, Womersley J. Body fat assessed from total body density and its estimation from skinfold thickness: measurements on 481 men and woman aged 16-72 years. Br J Nutr 1974;32:77-97.

13 Cotes JE. Lung function: assessment and application in medicine. 4th ed. Oxford: Blackwell, 1979.

14 Chinn DJ, Naruse Y, Cotes JE. Accuracy of gas analysis in lung function laboratories. Thorax 1986;41:133-7.

15 Jones RS, Meade F. A theoretical and experimental analysis of anomalies in the estimation of pulmonary diffusing capacity by the single breath method. $Q J \operatorname{Exp}$ Physiol 1961;46:131-43.

16 Astrand PO, Rodahl K. Textbook of work physiology. 2nd ed. London: McGraw-Hill, 1977:333-65.

17 Blackburn H, Taylor HL, Okamoto N, Rautaharj P, Mitchell PL, Kirkhof AC. Standardisation of the exercise electrocardiogram. A systematic comparison of chest lead configurations employed for monitoring during exercise. In: Karvonen MJ, Barry AJ, eds. Physical activity and the heart. Springfield, Illinois: Thomas, 1967:101-33.

18 Feldman HA, Brain JD, Harbison ML. Adjusting for confounded variables: pulmonary function and smoking in a special population. Environ Res 1987;43:25166.

19 Nie NH, Hull CH, Jenkins JC, Steinbrenner K, Bent DH. Statistical package for the social sciences. 2nd ed. New York: McGraw-Hill, 1975.

20 Frans A, Francis CH, Stanescu D, Nemery B, Prignot J, Braseur L. Transfer factor in patients with emphysema and lung fibrosis. Thorax 1978;33:539-40.

21 Coutts II, Gilson JC, Kerr IH, Parkes WR, TurnerWarwick M. Mortality in cases of asbestosis diagnosed by a pneumoconiosis medical panel. Thorax 1987;42:111-6.

22 Kreel L. Computed tomography of the thorax. Radiol Clin North Am 1978;16:575-84.

23 Yoshimura H, Hatakeyama M, Otsuji H, et al. Pulmonary asbestosis: CT study of subpleural curvilinear shadow. Radiology 1986;158:653-8. 